\title{
“CUSTOMIZED TITANIUM MESH VERSUS TITANIUM REINFORCED MEMBRANE IN LOCALIZED ALVEOLAR RIDGE AUGMENTATION WITH SIMULTANEOUSLY DELAYED IMPLANT PLACEMENT" A RANDOMIZED CLINICAL STUDY
}

\author{
Maha Saeed Ahmed Al shaikh*, Ahmed Yousef Gamal** and Ahmed El Sayed Hamed Amr***
}

\begin{abstract}
Aim: To compare two different alveolar ridge augmentation (ARA) approaches applied in conjunction with delayed dental implants regarding the enhancement of the buccolingual alveolar ridge width and the changes in alveolar crestal level radiographically.

Materials and Methods: 20 patients participated in this study; two groups received particulate bone graft simultaneously with delayed implant placement. Ten patients had received Customized titanium mesh (CTi) and ten patients had received titanium (Ti) reinforced membrane.

Results: Regarding the buccolingual ridge width by CBCT. Comparing the value of pre-post percent change between groups, revealed no statistically significant difference. In both groups, comparing pre and post value of buccolingual ridge width revealed a statistically significant increase. Regarding changes in alveolar crestal level by digital periapical radiography. In both groups, comparing pre and post value of alveolar crestal bone revealed no statistically significant difference.

Conclusion: Customized titanium mesh can be used successfully for ARA performed simultaneous with delayed implant placement as it enhances buccolingual alveolar ridge width and prevent alveolar crestal resorption.
\end{abstract}

KEYWORDS: Customized titanium mesh, Delayed implant, Guided bone regeneration, Ridge defect, Ti-reinforced membrane

\section{INTRODUCTION}

Successful implant therapy relies on a proper bone volume at the insertion site. (Chipasco et al., 2006). The presence of a bone width of at least
1-1.5 $\mathrm{mm}$ on both the buccal and lingual / palatal sides of the implant is required to achieve sufficient osseointegration and a successful treatment outcome (Scipioni et al., 1994; Nedir et al., 2004; Suh et.

\footnotetext{
* B.D.S, Faculty of Dentistry, Ain Shams University, 2011, Egypt, Cairo.

** Professor of Oral Medicine, Periodontology and Oral Diagnosis, Faculty of Dentistry, Ain Shams University, Egypt. *** Lecturer of Oral Medicine, Periodontology and Oral Diagnosis, Faculty of Dentistry, Ain Shams University, Egypt.
} 
al., 2005; Baffone et al., 2013; Bengazi et al., 2014). After removal of the tooth, the alveolar ridge undergoes significant remodeling cycle. It was defined in a systematic analysis that the mean width reduction of the alveolar ridge is $3.8 \mathrm{~mm}$ during the six months after tooth extraction, and the mean height reduction is $1.2 \mathrm{~mm}$ (Tan\& Wong, 2012).

Bone augmentations may take place simultaneously with (combined approach) or before (staged approach) placement of implants. The combined approach is favored if allowed by the clinical situation, since this strategy results in reduced morbidity, time and cost of treatment for the patient (Benic $\&$ Hammerle, 2014).

Guided bone regeneration (GBR) is based on guided tissue regeneration principles (GTR) (Nyman et al., 1980). GBR involves placing an occlusal barrier in such a way as to prevent the invasion of non-bone-forming cells from the surrounding soft tissues into the defect and at the same time allow time and space to repopulate the defect by the bone forming cells (Dahlin et al., 1990, 1998; Donos et al., 2004).

By using non-resorbable membranes (polytetrafluroethylene ; PTFE), the fill of defects was greater than the resorbable membranes, taking into account the following characteristics of PTFE membranes: better space provision effect, regulated barrier function time and absence of inflammatory resorption that negatively affects tissue regeneration (Hammerle \&Jung, 2003).

Titanium mesh (Ti-mesh) is another nonresorbable material valid for alveolar bone repair. In 1969, Boyne et al. inaugurated a titanium mesh to restore large osseous discontinuity defects. Titanium micromesh protect and preserve densely packed bone graft in the defects. It is the most resilient structurally in the membrane armamentarium, which ensured its function in protecting the graft, maintaining space until its removal, in addition to supporting the angiogenesis and cell ingrowth (
Lim et al., 2015). Raquel et al., 2016, found that horizontal ridge augmentation with titanium meshes performed simultaneously with dental implants was promising.

Owing to its high strength and rigidity, low density and corresponding low weight, its ability to withstand high temperatures and its corrosion resistance, titanium has been commonly used in various surgical applications (Degidi et al., 2003). Another common characteristic of the commercially available Ti-mesh membranes is their (millimeter range) macroporosity. This is believed to play a critical role in sustaining blood flow, and is believed to promote healing by enhancing wound stability through tissue integration and allowing extracellular nutrients to disperse through the mesh (Weng et al., 2000). In a systematic review by Briguglio et al., 2019, the use of particulate bone grafts with titanium mesh represented a successful method for the reconstruction of atrophic sites.

Ti-mesh provides an excellent approach for bone regeneration over other forms of membranes. However, the application of traditional Ti-mesh to a defect involves several steps: bending, trimming, and fixation. These processes are technically complex, time-consuming and have a strong impact on the regenerative outcomes (Rakhmatia et al., 2013). The present study applied a newly developed form of Ti-mesh; this customized Ti-mesh (CTi- mesh ) is ready for different types of defects and has stabilizing components that allow them to be easily fixed to the fixture of the implants. It was anticipated that Ti-meshs could be easier to control with this new design and thus minimize possible technical errors. CTi mesh approach postoperative follow-up showed that when it was used in simultaneous implant and grafting, the implant was stable with excellent osseointegration and the bone resorption at the surgical area was reconstructed (Jegham et al., 2017).

Hence, the purpose of this study was to determine the effect of a newly designed, self-stabilizing Timesh on buccal bone regeneration around the dental 
implant compared to non resorbable Ti-reinforced dense-PTFE membrane

\section{AIM OF THE STUDY}

\section{Primary objective:}

To compare two different approaches applied in conjunction with delayed dental implants regarding the enhancement of the buccolingual alveolar ridge width using cone beam computed tomography (CBCT).

1st approach: is the placement of customized titanium mesh (CTi- mesh )

2nd approach: is the placement of Ti-reinforced dense-PTFE membrane

\section{Secondary objective:}

To compare the formerly described approaches regarding the changes in alveolar crestal level (ACL) by digital periapical radiography (parallel technique).

\section{SUBJECTS AND METHODS}

\section{Patient selection}

Twenty patients were selected from the outpatient clinic in faculty of dentistry Ain shams university at the department of oral diagnosis, oral medicine and periodontology. The research ethics committee of Ain shams university faculty of dentistry had reviewed and accepted the proposal of the study. All patients received detailed written information about the study nature and treatment protocol then signed an informed consent form.

\section{Inclusion criteria}

- Medically free according to Burkett's health medical history questionnaire (Glick et al., 2008).

\footnotetext{
* Cti mesh neobiotech
}

- Single missing maxillary anterior tooth or premolar with history of extraction not less than 6 months.

- The buccolingual dimensions of the alveolar ridge allowed implant insertion but with slight bony dehiscence exposing the crestal 2-3 threads of the implant fixture which necessitated simultaneous bone augmentation at the same time of the implant insertion (Class 2 or 3 Benic \& Hammerle, 2014).

- The radiographic buccolingual width of the coronal third of the alveolar ridge ranges from 4 to $5 \mathrm{~mm}$ and it was measured at 2 points $3 \mathrm{~mm}$ and $5 \mathrm{~mm}$ apical to the alveolar crest then the mean was calculated while the radiographic buccolingual width of the apical third ranged from 9 to $13 \mathrm{~mm}$ and this was measured at point $8 \mathrm{~mm}$ and $10 \mathrm{~mm}$ apical to the alveolar crest then the mean was calculated.

- Dimensions mesiodistally shouldn't be less than the mesiodistal width of the missed tooth crown.

- Males or females from 20 to 40 years.

- Patients were not receiving any systemic drugs at the time of the examination and for at least four weeks prior to the study.

- Patients did not receive any drugs during the follow up period.

\section{Exclusion criteria:}

Smokers; residual infections in the edentulous area or apparent infection in a neighboring tooth; poor oral hygiene; cases that need staged augmentation approach (Class 4 and 5 Benic \& Hammerle, 2014).

\section{Patient grouping}

The twenty patients were divided into two groups: Ten patients, (Group 1, Test group) ARA was performed using customized titanium mesh*. 
Ten patients, (Group 2, Control group) ARA was performed using non resorbable titanium reinforced membrane*.

\section{Pre surgical preparation:}

Preoperative analysis included complete patient history, clinical examination, clinical photographs Fig (1).

Preoperative radiographic examination was done to the edentulous area using cone beam computed tomography (CBCT). One week before the implant placement, professional debridement and oral hygiene instructions were given to the patients.

Clinical re-evaluation of the case was done before starting the surgical procedures and any case that didn't follow the instructions was excluded.

\section{Surgical procedures}

Two surgeries were carried out for each patient; the bone augmentation and the implant placement were held in the same visit, and the second surgery was to remove the membrane or mesh after 4 months. After administration of local anesthesia, para-crestal horizonal incision technique using surgical blade number 15 , was applied placing the line of incision

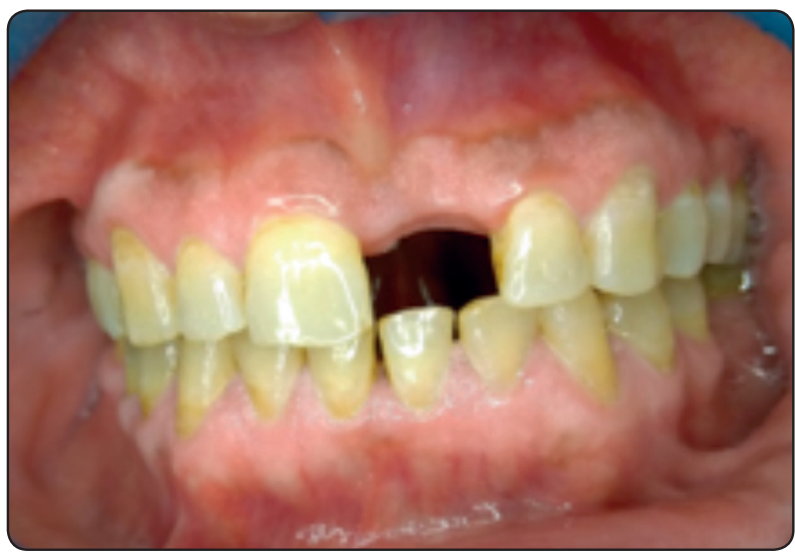

Fig. (1) Pre-operative clinical photo. toward the palatal aspect of the edentulous ridge in the maxilla. Sulcular incision was done buccal and palatal around the teeth mesial and distal to the edentulous area. Vertical releasing incisions mesial and distal extending beyond mucogingival junction were then performed followed by, full thickness flap elevation (Fig 2).

Initial drilling (800-1000 Rpm,30 N) was done using a pilot drill supplied in the implant surgical kit. After checking the position and the direction of the drill, sequential drilling was continued until reaching the final drill equivalent to the desired implant size. The implant ${ }^{* *}$ was installed till the implant platform was 2_3mm apical to the cementoenamel junction of neighboring teeth. A cover screw was secured over the implant after placement. The expected class 2 or 3 dehiscence defect was obtained (Benic \& Hammerle, 2014) Fig (3).

Graft material (particulate bone xenograft) Hypro-oss $^{* * *}$ in both groups was placed at the defect site Fig (4).

For the test group: after particulate graft placement, CTi mesh was placed and fixed with the cover screw, no need for additional screw, only adapt $\&$ burnish the margins Fig (5).

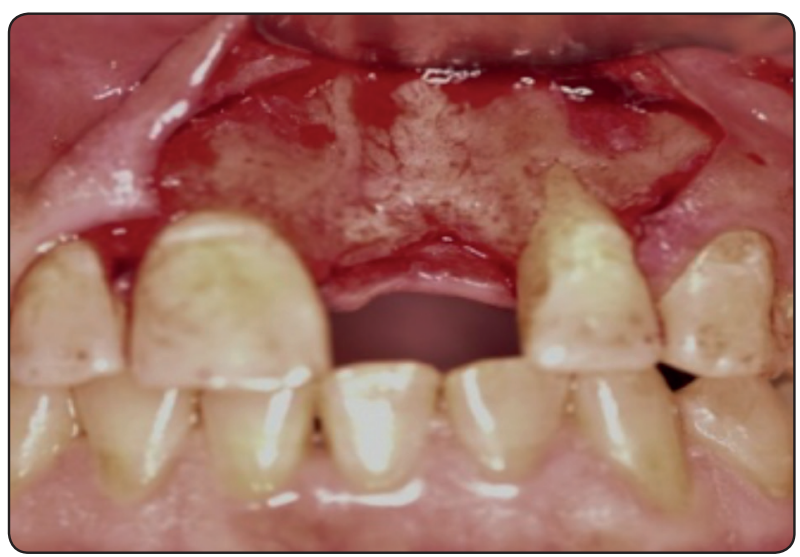

Fig. (2) Full thickness flap elevation.

\footnotetext{
* Ti 250 Osteogenicsbiomedical inc.USA

** Neo Biotech dental implant (IS-II active Fixture).

*** Hypro-Oss Granules (500-1000 Lm). Bioimplon Gmbh, Friedrichliststr,27, 35398 Giessen, German.
} 
For the control group: Ti. reinforced membrane was adapted over the grafted site. Then membrane tacks were used to assist the membrane stability one tack palatally and two tacks on mesial and distal of the buccal side of the membrane Fig (6).

Periosteal releasing incisions were performed, to aid in primary tension-free closure using interrupted 4-0 polypropylene suture.

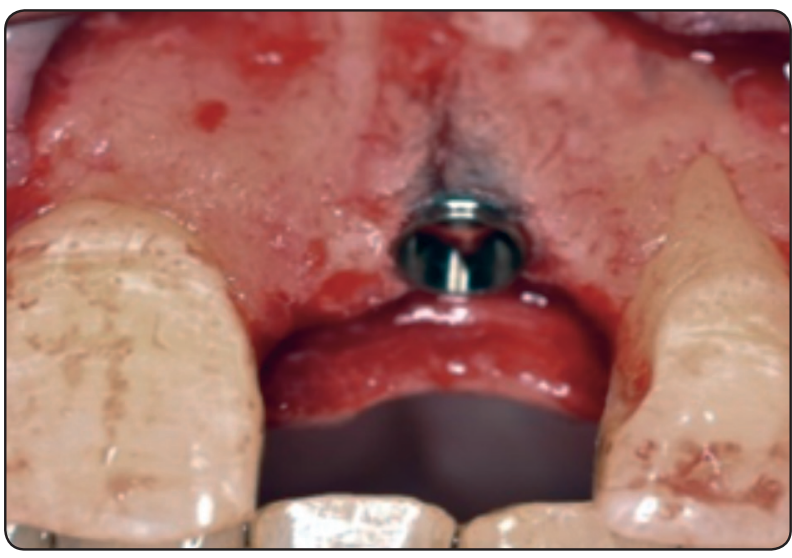

Fig. (3) Dehiscence defect

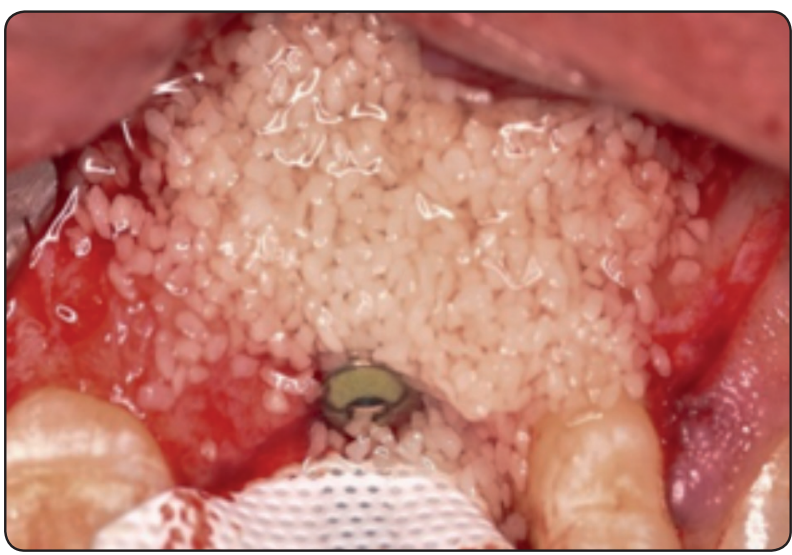

Fig. (4) Xenograft bone covering the dehiscence.

\section{Post-operative care}

Post-operative medications were prescribed to all patients, including amoxicillin and clavulanic acid ( Hibiotec , Amoun, Egypt) (1 g every 12 hours for 5 days) , non-steroidal anti-inflammatory drug (ibuprofen $600 \mathrm{mg}$ for a maximum of twice a day (Brufen, Kahira, Egypt) and chlorhexidine mouth

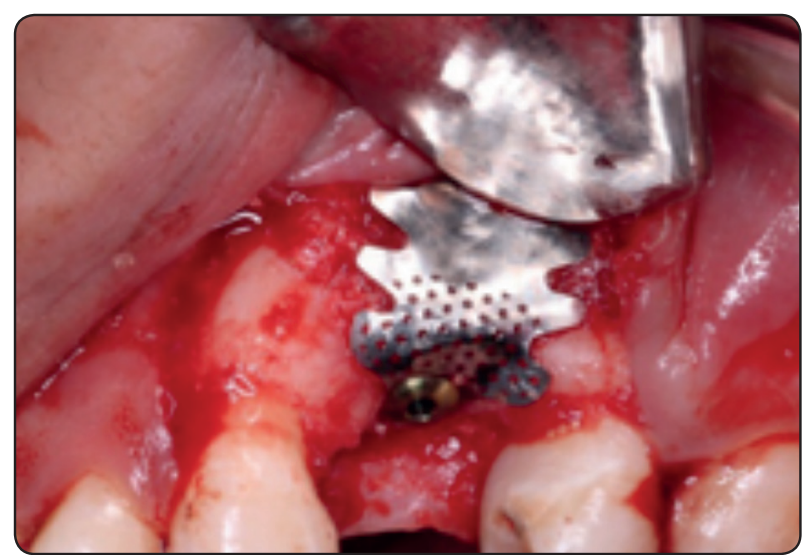

Fig. (5) CTi mesh covering the defect.

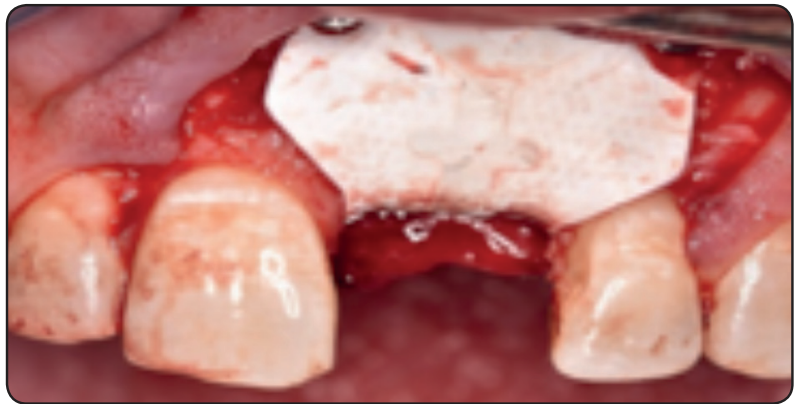

Fig. (6) Ti-reinforced membrane covering the defect.

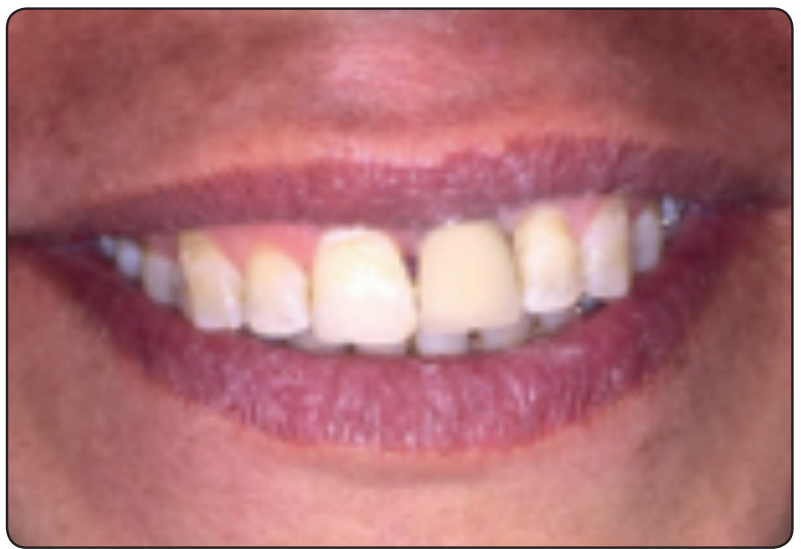

Fig. (7) after prosthesis delivery

rinse (Hexitol, ADCO, Egypt) $0.12 \%$ (twice a day). The patient is placed on warm saline rinses starting at the second day for the first 2-3 weeks to encourage normal flap healing without disturbing migrating cells (Huynh et al., 2016).

Oral hygiene measures were given to the patients and they were instructed to refrain from removing 
plaque by mechanical means at the surgical sites for 2 weeks and shouldn't use any removable partial denture during the first 4 months.

Sutures were removed 2 weeks postoperatively (Rojo et al., 2016). After 4 months, professional debridement was done then after one week, crestal incision was made after anaesthetizing the area with infiltration and removal of mesh or membrane was performed. Healing abutment was placed for two weeks. Then the prosthetic procedures started 2 weeks after healing abutment.

\section{Radiographical Assessment}

A) Radiographic evaluation of buccolingual alveolar ridge width changes:

Image reconstruction was performed using i-CAT software. Baseline CBCT was performed 1 week before the surgery. The second CBCT was performed four months after augmentation during prosthetic steps. (Gluckman \& Du Toit, 2014). On the same CBCT, 3 sagittal views were used for evaluation and at each sagittal view 2 buccolingual measures were taken.

\section{B) Radiographic evaluation of alveolar crest level changes:}

This was performed using digital periapical radiograph using long-cone paralleling technique. Baseline measure: Day zero, immediately after implant insertion; $\mathrm{ACL}_{1}$. Follow up measure: Month 4, 1week before removal of mesh/ membrane and placement of healing abutment; $\mathrm{ACL}_{2}$.

ACL represent the distance from the apex of the implant (fixed reference point) to the first implantshoulder to bone contact. To determine ACL changes by time, ACLs were measured mesially and distally to each implant and the mean of both represent $\mathrm{ACL}_{1}$ at zero day and $\mathrm{ACL}_{2}$ at 4 months.

\section{Statistical Analysis}

Values were presented as mean and standard deviation (SD), median, min. max and confidence intervals. Data were explored for normality using Kolmogorov-Smirnov test of normality. The results of Kolmogorov-Smirnov test indicated that most of data of CBCT were normally distributed (parametric data), while digital paralleling data were nonparametric.

For CBCT, Unpaired $\mathrm{t}$ test was used for intergroup comparisons, while paired $t$ test was used for intragroup comparisons.

Mann Whitney U test was used for intergroup comparison regarding paralleling results and percent change of CBCT and paralleling, while Wilcoxon signed rank was used for intragroup comparison of paralleling results

\section{RESULTS}

1- Alveolar ridge buccolingual width changes by CBCT:

\section{a-Comparison between groups}

- Pre-treatment, Independent t test revealed no significant difference between groups $(\mathrm{p}=0.318)$ (Table 1).

- Post treatment, Independent t test revealed no significant difference between groups $(\mathrm{p}=0.394)$ (Table 1).

A greater percent increase was recorded in $\mathrm{Ti}$ reinforced group. Mann Whitney $U$ test revealed no significant difference between groups $(\mathrm{p}=0.354)$ (Table 1).

- b. Comparison between the radiographical buccolingual width within the same group:

- In CTI group, comparing pre and post value of buccolingual width using paired t test revealed a significant increase $(2.56 \pm 0.86),(\mathrm{P}=0.00)$ (Table 2).

- In Ti reinforced group, comparing pre and post value of buccolingual width using paired $t$ 
test revealed a significant increase $(2.65 \pm 0.95)$, $(\mathrm{P}=0.00)$ (Table 2).

\section{2- Changes in alveolar crestal level by digital periapical radiograph:}

\section{a) Comparison between groups:}

- Pre-treatment, a higher median value was recorded in Ti reinforced group. Mann Whitney $\mathrm{U}$ test revealed no significant difference between groups $(\mathrm{p}=0.444)$ (Table 3$)$.

- Post treatment, a higher median value was recorded in Ti reinforced group. Whitney $\mathrm{U}$ test revealed no significant difference between groups $(\mathrm{p}=0.630)$ (Table 3$)$.

A greater median value of percent decrease was recorded in Ti reinforced group. Mann Whitney $\mathrm{U}$ test revealed no significant difference between groups ( $\mathrm{p}=0.963)$ (Table 3).

\section{b) Comparison of alveolar crestal level by digital periapical radiography within the same group:}

- In CTi group, comparing pre and post value of alveolar crestal bone level using Wilcoxon signed Rank test revealed the same median value, with no significant difference, $(\mathrm{P}=0.075)$ (Table 4).

- In Ti reinforced group, comparing pre and post value of alveolar crestal bone level using Wilcoxon signed Rank test revealed a decrease in the median value after treatment, with no significant difference, $(\mathrm{P}=0.310)$ (Table 4$)$.

TABLE (1) Descriptive statistics and comparison of values of changes in radiographical buccolingual width by CBCT pre -post, difference and percent change after treatment in both groups.

\begin{tabular}{|c|c|c|c|c|c|}
\hline \multicolumn{2}{|c|}{ Groups } & $\begin{array}{l}\text { Buccolingual } \\
\text { width pre }\end{array}$ & $\begin{array}{c}\text { Buccolingual } \\
\text { width post }\end{array}$ & $\begin{array}{c}\text { Difference } \\
\text { Between pre-post }\end{array}$ & Percent change \\
\hline \multirow{7}{*}{ CTi group } & Mean & 4.87 & 7.42 & 2.56 & 55.37 \\
\hline & Std. Error of Mean & .31 & .27 & .29 & 7.21 \\
\hline & Median & 4.80 & 7.60 & 2.80 & 65.22 \\
\hline & Std. Deviation & .92 & .80 & .86 & 21.64 \\
\hline & $95 \% \mathrm{CI}$ & $4.16-5.57$ & $6.81-8.04$ & $1.89-3.22$ & 38.74-72.01 \\
\hline & Minimum & 3.50 & 6.30 & 1.00 & 14.29 \\
\hline & Maximum & 7.00 & 8.50 & 3.50 & 80.00 \\
\hline \multirow{7}{*}{ Ti reinforced group } & Mean & 4.44 & 7.09 & 2.65 & 63.15 \\
\hline & Std. Error of Mean & .27 & .27 & .32 & 9.39 \\
\hline & Median & 4.30 & 7.10 & 3.00 & 73.81 \\
\hline & Std. Deviation & .82 & .81 & .95 & 28.16 \\
\hline & $95 \% \mathrm{CI}$ & $3.81-5.07$ & $6.47-7.71$ & $1.91-3.38$ & $41.51-84.80$ \\
\hline & Minimum & 3.50 & 5.50 & 1.20 & 23.15 \\
\hline & Maximum & 6.09 & 8.40 & 2.56 & 55.37 \\
\hline \multirow{2}{*}{$\begin{array}{c}\text { Comparison between } \\
\text { groups }\end{array}$} & $\mathrm{t}$ & 1.03 & 0.88 & 0.21 & --- \\
\hline & $\mathrm{P}$ & $0.318 \mathrm{~ns}$ & $0.394 \mathrm{~ns}$ & $0.836 \mathrm{~ns}$ & $0.354 \mathrm{~ns}$ \\
\hline
\end{tabular}

Significance level $p \leq 0.05$, ns=non-significant 95\% CI=95\% confidence interval

Independent t test was used to compare buccolingual width values between groups.

Mann-Whitney $U$ test was used to compare difference and percent change after treatment between groups. 
TABLE (2) Comparison of values of buccolingual width pre -post within the same group (paired $t$ test).

\begin{tabular}{|c|c|c|c|c|c|c|c|c|}
\hline \multirow{3}{*}{\multicolumn{2}{|c|}{ Groups }} & \multicolumn{5}{|c|}{ Paired Differences } & \multirow{3}{*}{$\mathrm{t}$} & \multirow{3}{*}{$P$} \\
\hline & & \multirow[t]{2}{*}{ Mean } & \multirow{2}{*}{$\begin{array}{c}\text { Std. } \\
\text { Deviation }\end{array}$} & \multirow{2}{*}{$\begin{array}{l}\text { Std. Error } \\
\text { Mean }\end{array}$} & \multicolumn{2}{|c|}{$\begin{array}{c}\text { 95\% Confidence Interval of the } \\
\text { Difference }\end{array}$} & & \\
\hline & & & & & Lower & Upper & & \\
\hline CTI Group & pre - post & 2.56 & .86 & .29 & 1.89 & 3.22 & 8.91 & $.00 *$ \\
\hline Ti reinforced Group & pre -post & 2.65 & .95 & .32 & 1.91 & 3.38 & 8.32 & $.00 *$ \\
\hline
\end{tabular}

Significance level $p \leq 0.05$, *significant

TABLE (3) Descriptive statistics and comparison of values of alveolar crestal level (ACL) pre -post and difference after treatment in both groups (Mann whitney U test).

\begin{tabular}{|c|c|c|c|c|c|}
\hline \multicolumn{2}{|l|}{ Groups } & $\begin{array}{l}\text { ACL } \\
\text { pre }\end{array}$ & $\begin{array}{l}\text { ACL } \\
\text { post }\end{array}$ & $\begin{array}{c}\text { Difference } \\
\text { Between pre-post }\end{array}$ & $\begin{array}{l}\text { Percent } \\
\text { change }\end{array}$ \\
\hline \multirow{7}{*}{ CTI group } & Mean & 12.00 & 11.49 & -.51 & -4.33 \\
\hline & Std. Error of Mean & .25 & .36 & .23 & 1.94 \\
\hline & Median & 11.50 & 11.50 & -.36 & -3.13 \\
\hline & Std. Deviation & .75 & 1.09 & .68 & 5.82 \\
\hline & $95 \% \mathrm{CI}$ & $11.42-12.58$ & $10.65-12.32$ & $-1.04-.01$ & $-8.80-.14$ \\
\hline & Minimum & 11.50 & 10.12 & -1.38 & -12.00 \\
\hline & Maximum & 13.00 & 13.00 & .48 & 4.17 \\
\hline \multirow{7}{*}{ Ti reinforced group } & Mean & 12.15 & 11.67 & -.48 & -3.67 \\
\hline & Std. Error of Mean & .29 & .40 & .44 & 3.56 \\
\hline & Median & 12.07 & 11.87 & -.45 & -3.52 \\
\hline & Std. Deviation & .83 & 1.13 & 1.26 & 10.07 \\
\hline & $95 \% \mathrm{CI}$ & $11.46-12.85$ & $10.73-12.62$ & $-1.53-.57$ & $-12.09-4.75$ \\
\hline & Minimum & 10.68 & 10.33 & -2.41 & -18.54 \\
\hline & Maximum & 13.00 & 13.77 & 1.63 & 13.43 \\
\hline $\begin{array}{c}\text { Comparison between } \\
\text { groups }\end{array}$ & $\mathrm{P}$ & $.444 n s$ & $.630 \mathrm{~ns}$ & $.961 \mathrm{~ns}$ & $.963 \mathrm{~ns}$ \\
\hline
\end{tabular}

Significance level $p \leq 0.05, n s=$ non-significant

$95 \%$ CI=95\% confidence interval

TABLE (4) Comparison of values of alveolar crestal level (pre -post) within the same group (Wilcoxon signed Rank test).

\begin{tabular}{|c|c|c|c|c|c|c|c|}
\hline \multirow{3}{*}{ Groups } & \multirow{3}{*}{ ACL } & \multicolumn{5}{|c|}{ Paired Differences } & \multirow{3}{*}{$P$} \\
\hline & & \multirow{2}{*}{ Mean } & \multirow{2}{*}{ Std. Deviation } & \multirow{2}{*}{$\begin{array}{l}\text { Std. Error } \\
\text { Mean }\end{array}$} & \multicolumn{2}{|c|}{$\begin{array}{l}95 \% \text { Confidence Interval } \\
\text { of the Difference }\end{array}$} & \\
\hline & & & & & Lower & Upper & \\
\hline CTI group & pre - post & .51 & .68 & .23 & -.01 & 1.04 & $0.075 \mathrm{~ns}$ \\
\hline Ti reinforced group & pre -post & .48 & 1.26 & .44 & -.57 & 1.53 & $0.310 \mathrm{~ns}$ \\
\hline
\end{tabular}

Significance level $p \leq 0.05$, ns=non-significant 


\section{DISCUSSION}

The GBR therapeutic technique requires the surgical positioning of a cell occlusive membrane facing the bone surface (Dahlin et al., 1988). The membrane provides an area for the osteoprogenitor cells (Linde et al., 1993; Karring et al., 1993).

This study included 20 patients who were allocated into two different groups. Sample size determination based on a 0.05 power 0.8 . The power of this study $=80 \%$ - confidence $=95 \%$. Accepted error $=5 \%$.

The age group was between 20-40 years while older patients were excluded as the aging process involves changes in a person 's physiological, pathological, social, and psychological conditions (Rowe \& Kahn, 1987).

To prevent any adverse effects of smoking on the final outcome, all patients in our study were non-smokers, the evidence showed that smokers are at higher risk of implant failure, peri-implantitis (Cochran et al., 2009; Lin et al., 2014). All patients were systemically free and received no systemic antibiotics or corticosteroids to avoid any effects on bone metabolism and periodontal status, and to standardize the capacity for healing (Glick et al., 2018).

The buccolingual dimensions of the alveolar ridge which had been chosen in this study allowed implant insertion but with slight bony dehiscence exposing the buccal crestal 2-3 threads of the implant fixture which necessitated simultaneous bone augmentation at the same time of the implant insertion (Class 2 or 3 Benic \& Hammerle, 2014).

In this study, dental implants were limited to maxillary anterior and premolar areas owing to better visibility than the lower jaw (Adell, 1974; Breine and Branemark, 1980; Adell et al., 1981).

Regarding the timing of GBR, in our research a single-stage protocol was followed and the reconstructive GBR procedure was performed simultanously with the implantation to reduce total treatment time and overall invasiveness of the surgical procedure (Hellem et al., 2003). This was made possible by the fact that the horizontal bone defect was mild (Class 2 or 3 Benic \& Hammerle, 2014), the edentulism was restricted to a single tooth of the maxilla, and the amount of graft necessary to fill the defect was limited, due to the volume taken up by the implant itself.

Of the more widely known materials, the high density polytetrafluoroethylene (d-PTFE) selected in our study provides separation between the soft tissue and the grafted bone, helps to seal the wound if the primary union is not achieved and stabilize the graft to support new vessels' growth (Strietzel et al., 2006; Hoffmann et al., 2008).

Titanium-reinforced d-PTFE membranes have been used for structural durability preserving the required space and promoting the stability of the graft. (Cytoplast barrier membranes. Osteogenics; updated 2014). For tenting and space maintenance this membrane can be moulded and shaped.

In this study customized titanium mesh (CTi) were used (test group) secured in place by the implant fixture component itself (cover screw). Studies found that titanium mesh protects and retains closely packed bone graft and found no invasion or displacement of the graft by the soft tissues that surround the titanium mesh. In addition to supporting angiogenesis and cell development, it is the most structurally resilient in the membrane armamentarium which ensured its role in protecting the graft, maintaining space until removal (Von Arx and Kurt, 1998; Her et al., 2012; Lim et al., 2015).

Another common feature of $\mathrm{CTi}$ mesh is its macro-porosity, in the millimeter range (around $1 \mathrm{~mm}$ ) (Lim et al., 2015). Chvapil et al., (1969), suggested that pores require more than $100 \mu \mathrm{m}$ for the rapid penetration of highly vascular connective tissue and that smaller pores appear to fill with more 
avascular tissue. Other studies have shown that macropores play a critical role in maintaining blood supply and in allowing extracellular nutrients to spread across the mesh (Weng, et al., 2000).

The present study showed non-significant differences in all of the radiographical parameters between groups at baseline, this is of importance as it indicates that there was no difference in selection and exclusion criteria at the beginning of the study between both groups, a finding that ensured comparable treatment outcomes during the follow up periods.

Intra group statistical analysis demonstrated that from baseline to four months, the two treatment modalities revealed statistically significant increase in alveolar ridge buccolingual width. Regarding group one of CTi mesh; this was in accordance to systematic review by Briguglio et al., 2019, which showed that the regenerative procedures performed through the use of particulate grafts associated with a titanium mesh represented a predictable method for the rehabilitation of atrophic sites.

Regarding the intra group statistical analysis of group 2 Ti-reinforced membrane; this was in accordance to Urban et al., 2014, using titanium reinforced d-PTFE in ridge augmentation, which discover that all treated defect sites exhibit excellent bone formation and none of the cases demonstrated bone resorption throughout the follow up period.

Intra group statistical analysis regarding the alveolar crestal level (ACL) revealed no statistically significant change in the ACL in both treatment modalities. Regarding $\mathrm{CTi}$ mesh group; this was in accordance to previous literature, Bartolomeo et al., 2001, which found no unwanted effects on crestal bone levels using titanium micromesh used simultaneous with implant placement.

Regarding Ti-reinforced membrane group; this was in accordance to previous study where followup radiographs taken up to 24 months after GBR using Ti-reinforced d-PTFE simultaneous with implant placement showed complete maintenance of the peri-implant bone crestal levels without any sign of bone resorption. The grafted site was perfectly able to support the functional loading of the implant (Cucchi and Ghensi, 2014).

Inter group comparison of percent change of radiographical alveolar ridge buccolingual width between the two groups revealed the mean of the CTi group was $+55.37 \%$ and the Ti-reinforced group was $+63.15 \%$ which by statistical analysis showed no statistically significance difference; these results were confirmed by the systematic review performed by Milinkovic \& Cordaro in 2014.

Inter group percent change of ACL between the two groups revealed the median value of the CTi group was -3.13 and the Ti-reinforced membrane was -3.52 which by statistical analysis showed no difference.

Finally, there is no statistically significant difference between the two groups radiographically both in the alveolar bone buccolingual width changes and alveolar crestal level changes. But as our study were investigating volumetric dimensional changes rather than quality of the new formed bone, the quality of regenerated bone between groups may differ taking in consideration the pseudoperiosteum found in the Ti-reinforced membrane group after membrane removal and not found in the mesh group. Unfortunately, we didn't analyze bone quality which is recommended to be carried in further studies.

\section{CONCLUSION}

Customized titanium mesh can be used successfully for alveolar ridge augmentation performed simultaneous with delayed implant placement as it:

1. Enhance buccolingual ridge width of the alveolar ridge.

2. Prevent alveolar crestal resorption. 
3. Could provide superior defect stability evidenced by the absence of the ti-mesh associated pseudo-periosteum.

\section{REFERENCES}

- Adell R. Regeneration of the periodontium. An experimental study in dogs. Scand. J. Plast. Reconstr. Surg, (1974); 8: Suppl, II.

- Adell, R., Lekholm, U., Rockler, B., and Brånemark, P.I., A 15-year study of osseointegrated implants in the treatment of the edentulous jaw. International Journal of Oral Surgery, (1981); 10 (6): 387-416.

- Baffone G.M., Botticelli D., Pereira F.P., Favero G., Schweikert M. and Lang N.P., Influence of buccal bony crest width on marginal dimensions of peri-implant hard and soft tissues after implant installation. An experimental study in dogs. Clinical Oral Implants Research, (2013); 24: 250-254.

- Bartolomeo Assenza, Maurizio Piattelli, Antonio Scarano, Giovanna Iezzi, Giovanna Petrone and Adriano Piattelli, Localized ridge augmentation using titanium micomesh, Journal of Oral Implantology, (2001); XXVII: 287-292.

- Bengazi F., Botticelli D., Favero V., Perini A., Urbizo Velez, J. and Lang N.P., Influence of presence or absence of keratinized mucosa on the alveolar bony crest level as it relates to different buccal marginal bone thicknesses. An experimental study in dogs. Clinical Oral Implants Research, (2014); 25: 1065-1071.

- Benic G. I., and Hammerle C. H. F., Horizontal bone augmentation by means of guided bone regeneration, Periodontology 2000, (2014); 66(1):13-40.

- Boyne PJ, Cole MD, Stringer D. and Shafqat JP., A technique for osseous restoration of deficient edentulous maxillary ridges. J Oral Maxillofac Surg., (1969); 43:87-91.

- Breine u. and Branemark P.-I., Reconstruction of alveolar jaw bone. An experimental and clinical study of immediate and preformed autologous bone grafts in combination with osseointegrated implants. Scand. J. Plast. Reconstr, Surg, (1980); 14: 23-48.

- Briguglio F., Falcomata D., Marconcini S., Fiorillo L., Briguglio R., and Farronato D., The Use of Titanium Mesh in Guided Bone Regeneration: A Systematic Review. International Journal of Dentistry, (2019); Article ID 9065423,8 pages.
- Chiapasco M., Ferrini F., Casentini P., Accardi S. and Zaniboni M., Dental implants placed in expanded narrow edentulous ridges with the Extension Crest device. A 1-3year multicenter follow-up study. Clin Oral Implants Res. (2006); 17:265-272.

- Chvapil M., Holusa R., Kliment K., and Stoll M., Some chemical and biological characteristics of a new collagen polymer compound material, Journal of Biomedical Materials Research, (1969); Vol 3:315-332.

- Cochran, Schou, Heitz-Mayfield, Bornstein, Salvi and Martin, Consensus statements and recommended clinical procedures regarding risk factors in implant therapy. The International Journal of Oral \& Maxillofacial Implants, (2009); 24: Suppl, 86-89.

- Cucchi A. and Ghensi P., Vertical Guided Bone Regeneration using Titanium-reinforced d-PTFE Membrane and Pre-hydrated Cortico-cancellous Bone Graft. The Open Dentistry Journal, (2014); 8:194-200.

- Dahlin C, Linde A, Gottlow J, Nyman S., Healing of bone defects by guided tissue regeneration. Plast Reconstructive Surg., (1988); 81(5): 672-676.

- Dahlin, C., Gottlow, J., Linde, A. and Nyman, S., Healing of maxillary and mandibular bone defects using a membrane technique. An experimental study in monkeys. Scandinavian Journal of Plastic and Reconstructive Surgery and Hand Surgery, (1990); 24:13-19.

- Dahlin, C., Simion, M., Nanmark, U. and Sennerby, L., Histological morphology of the e-ptfe, tissue interface in humans subjected to guided bone regeneration in conjunction with oral implant treatment. Clinical Oral Implants Research, (1998);

- Degidi M, Scarano A and Piattelli A., Regeneration of the alveolar crest using titanium micromesh with autologous bone and a resorbable membrane. J Oral Implantol, (2003); 29:86.

- Donos N., Lang N.P., Karoussis I.K., Bosshardt D., Tonetti M. and Kostopoulos L., Effect of GBR in combination with deproteinized bovine bone mineral and/or enamel matrix proteins on the healing of critical-size defects. Clinical Oral Implants Research, (2004); 15: 101-111.

- Glick M, Greenberg MS, Ship JA. Introduction to oral medicine and oral diagnosis: evaluation of the dental patient . Burkets oral medicine 2008; 11:1-16 
- Gluckman H. and J. Du Toit, Guided bone regeneration using a titanium membrane at implant placement: A case report and literature discussion International Dentistry African edition, (2014); vol. 4, no. 6 .

- Hammerle C. H. F., and Jung R. E., Bone augmentation by means of barrier membranes, Periodontology 2000 , (2003);vol.33:36-53.

- Hellem S, Astrand P, Stenström B, Engquist B, Bengtsson M. and Dahlgren S., Implant treatment in combination with lateral augmentation of the alveolar process: a 3-year prospective study. Clin Implant Dent Relat Res., (2003); 5:233-240.

- Her S., Kang T., and Fien M. J., Titanium mesh as an alternative to a membrane for ridge augmentation, Journal of Oral and Maxillofacial Surgery, (2012); 70, no. 4: 803-810.

- Hoffmann O, Bartee BK, Beaumont C, Kasaj A, Deli G. and Zafiropoulos GG., Alveolar bone preservation in extraction sockets using non-resorbable d-PTFE membranes: a retrospective non-randomized study. J Periodontol. (2008); 79(8):1355-69.

- Huynh NC-N, Everts V, Leethanakul C, Pavasant P. and Ampornaramveth RS., Rinsing with Saline Promotes Human Gingival Fibroblast Wound Healing In Vitro. PLoS one. (2016); 11(7): e0159843.

- Jegham H., Masmoudi R., Ouertani H., Blouza I., Turki S., Khattech M. B., (2017). Ridge augmentation with titanium mesh: A case report, Military Hospital, No 8, Univers street, Tunis, Tunisia, J Stomatol Oral Maxillofac Surg $118 ; 181-186$

- Karring T., Nyman S., Gottlow J. and Laurell L., Development of the biological concept of guided tissue regeneration-animal and human studies. Periodontology 2000, (1993); 1: 26-35.

- $\quad$ Lim H. C., Kim M. S., Yang C., Lee J. S., Hong J. Y., Choi S. H., and Jung U. W., The Effectiveness of a Customized Titanium Mesh for Ridge Preservation with Immediate Implantation in Dogs. Clinical Implant Dentistry and Related Research, (2015); 17:e652-e660.

- Lin, Chan, Bashutski and Wang, The Effect of Flapless Surgery on Implant Survival and Marginal Bone Level: A Systematic Review and MetaAnalysis. Journal of Periodontology, (2014); 85(5):e91-e103.

- Linde P., Alberius C., Dahlin K., Bjurstam, and Y. Sundin, Osteopromotion: a soft-tissue exclusion principle using a membrane for bone healing and bone neogenesis, Journal of Periodontology, (1993); 64, no. 11:1116-1128.

- Milinkovic I., and Cordaro L., Are there specific indications for the different alveolar bone augmentation procedures for implant placement? A systematic review. International Journal of Oral \& Maxillofacial Surgery, (2014); 43(5):606-625.

- Nedir R, Bischof M, Briaux JM, Beyer S, Szmukler-Moncler S. and Bernard JP., A 7-year life table analysis from a prospective study on ITI implants with special emphasis on the use of short implants. Results from a private practice. Clin Oral Implants Res. (2004); 15:150-157.

- Nyman S, Karring T, Lindhe J and Planten S., Healing following implantation of periodontitis-affected roots into gin- gival connective tissue. J Clin Periodontol., (1980); 7(5):394-401.

- Osteogenics biomedical (online). Cytoplast barrier membranes. Osteogenics; (updated 2014; cited 2014 October 25). Available from: https:www.osteogenics.com/v/productgroup/Ti-250-Titanium Reinforced/vb.

- Rakhmatia Y. D., Ayukawa Y., Furuhashi A., and Koyano K., Current barrier membranes: Titanium mesh and other membranes for guided bone regeneration in dental applications. Journal of Prosthodontic Research, (2013); 57(1): 3-14.

- Raquel Zita Gomes, Andres Paraud Freixas, Chang-Hun Han, Sohueil Bechara, and Isaac Tawil, (2016). Alveolar Ridge Reconstruction with Titanium Meshes and Simultaneous Implant Placement: A Retrospective, Multicenter Clinical Study. BioMed Research International, 5126838, 12 pages.

- Rojo, Prados-Frutos, Manchón, Rodríguez-Molinero, Sammartino, Calvo Guirado and Gómez-De Diego, Soft Tissue Augmentation Techniques in Implants Placed and Provisionalized Immediately: A Systematic Review. BioMed Research International, (2016).

- Rowe J. and Kahn R., Human aging: usual and successful. Science, (1987); 237(4811): 143-149.

- Scipioni A., Bruschi G.B. and Calesini G., The edentulous ridge expansion technique: a five- year study. International Journal of Periodontics and Restorative Dentistry, (1994); 14:451-459.

- Strietzel FP, Khongkhunthian P, Khattiya R, Patchanee P. and Reichart PA., Healing pattern of bone defects covered 
by different membrane types--a histologic study in the porcine mandible. J Biomed Mater Res B Appl Biomater., (2006); 78(1):35-46.

- Suh J.J., Shelemay A., Choi S.H. and Chai J.K., Alveolar ridge splitting: a new microsaw technique. International Journal of Periodontics and Restorative Dentistry, (2005); 25:165-171.

- Tan WL, Wong TL, Wong MC. And Lang NP., A systematic review of post-extraction alveolar hard and soft tissue dimensional changes in humans. Clin Oral Implants Res., (2012); 23:1-21.

- Urban Istvan A., Lozada Jaime L., Jovanovic Sascha A.,
Nagursky Heiner and Nagy Katalin, Vertical Ridge Augmentation with Titanium-Reinforced, Dense-PTFE Membranes and a Combination of Particulated Autogenous Bone and Anorganic Bovine Bone-Derived Mineral: A Prospective Case Series in 19 Patients. International Journal of Oral \& Maxillofacial Implants, (2014); 29:185-193.9p.

- Von Arx T. and Kurt B., Implant placement and simultaneous peri-implant bone grafting using a micro-titanium mesh for graft stabilization. Int J Periodont. Restor. Dent., (1998); 18:117-127.

- Weng D, Hurzeler MB, Quinones CR., Contribution of the periosteum to bone formation in guided bone regeneration. Clin Oral Implants Res., (2000); 11:546-54. 